\title{
SUCCESS AND FAILURE IN FLEXIBLE BUILDING
}

\section{Rob Geraedts}

\begin{abstract}
In the present demand-driven market, consumers play a key role. Players in the house-building market, as in other sectors, need to listen to the consumer's requirements - and these are continually changing. The real estate sector is rather rigid in its practices, yet those working in it will need to respond to the fluctuating wishes and demands of their consumers. One possible response is to adopt a flexible building strategy. Industrial Flexible Demountable (IFD) building has recently been a subject of debate in the Dutch construction sector. This is a special type of construction involving experimental projects, experimentation being the first step in optimising a renewed production process or product. The building process is currently subject to various construction-related and organisational obstacles. This means that, in some cases, the objectives (which are focused on consumer-oriented building practices) were not being achieved. It was necessary to identify the problem areas and to consider the available opportunities for optimising the building process in future IFD house-building projects. The results of this study have been incorporated into guidelines containing a step-by-step plan. This plan sets out practical recommendations for market actors who wish to initiate an IFD house-building project. This study's conclusions and recommendations form the basis for the seven stages that such parties will need to complete before starting on such a project.
\end{abstract}

Keywords: Industrial, Flexible, Demountable, Sustainable, Housing.

\section{INDUSTRIAL FLEXIBLE DEMOUNTABLE BUILDING}

One of the themes currently featuring in the Dutch construction sector is Industrial Flexible Demountable (IFD) building. A national experimental programme was established in 1999 with the objective of encouraging industry, as well as the supply-side and the demand-side of the market, to adopt IFD building. The programme itself was the brainchild of the Steering Committee for Experiments in Public Housing (SEV). It was they who organised the recruitment and selection of projects. Part of the cost of these projects is financed by grants from the Ministry of Housing, Spatial Planning and Environment (VROM) and the Ministry of Economic Affairs (EZ). A wide range of institutional and incidental clients, such as housing associations, project developers, retail companies, manufacturers, and other companies, submitted 69 projects. Several projects are devoted to consumeroriented construction. This means freedom of choice for the initial user and adaptability to changing housing needs throughout the lifecycle of the building (Bouwmeester 2004). IFD Building can be defined as follows (Crone 2007): IFD building is a construction method for creating flexible housing, in which the user is free to choose the size of the dwelling in question, together with details of its layout, built-in facilities, and finishing. In addition, such dwellings can be adapted to changing housing needs while their users are in residence. During the construction stage of the property in question, use is made of industrially manufactured products that can be easily assembled or disassembled on site. Clients are motivated to participate in IFD programme for the following reasons (figure 1):

An initial survey on the basis of this publication (Crone 2007) led to the following preliminary conclusions:

- Many IFD house-building projects failed to achieve the original objectives which underpinned these projects at their inception;

- Obstacles in the building process caused projects to be suspended when only half complete, gave rise to construction delays, or led to a different end-result than that intended;

- In many cases, the IFD concept did not progress beyond the experimental stage. No further development took place. 


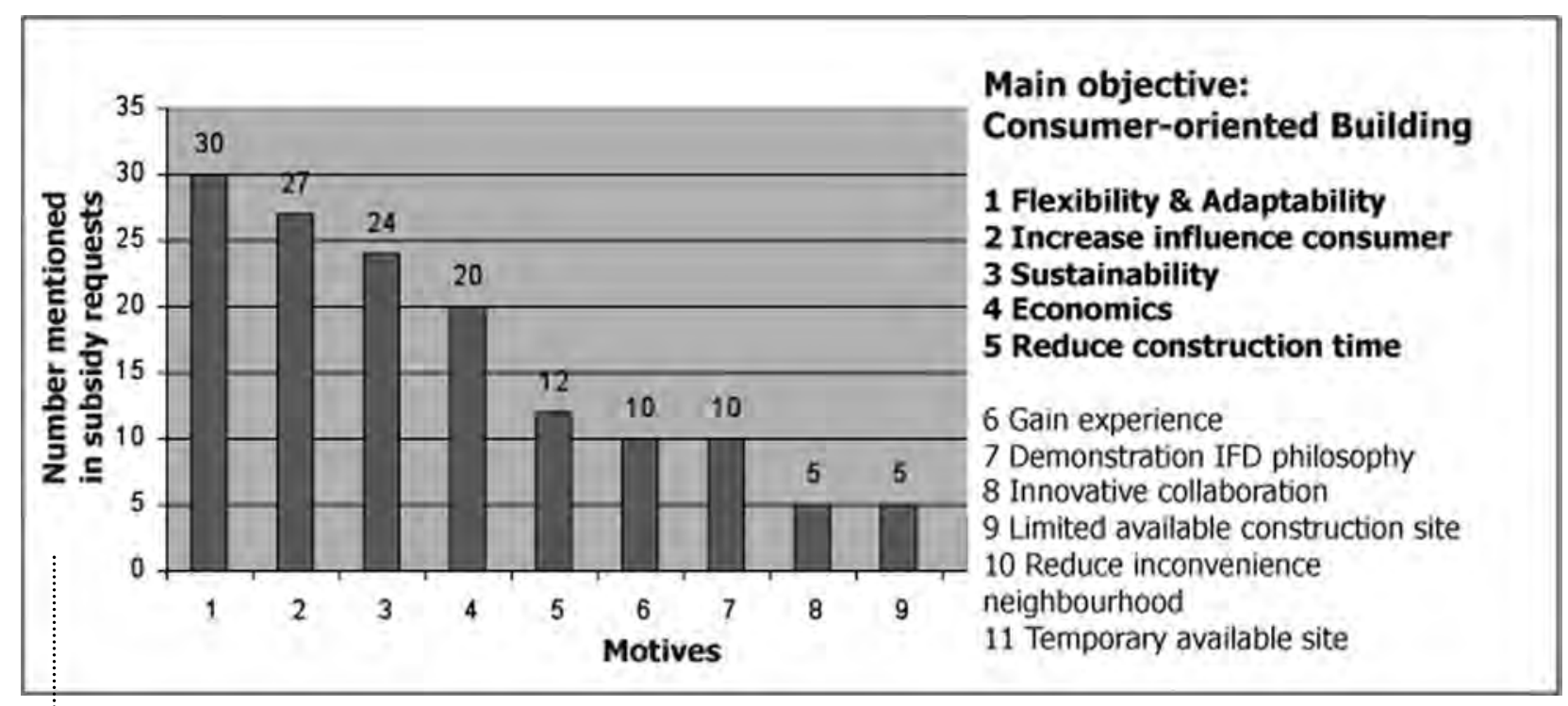

Figure 1. Clients' motives in opting for IFD Building (by Decisio 2006)

\section{Lack of familiarity with the IFD concept}

It appears that relatively few people are familiar with IFD building. The major clients are well informed in this regard, however. In addition, the limited use of IFD building makes its acceptance more difficult, especially among small businesses and construction companies. IFD building is a "generic term involving many and varied solutions, lines of development and manifestations" (Desicio 2006).

\section{Technical aspects of building}

The choice of smart construction techniques was an important aspect of the experimental IFD housebuilding projects. A search was conducted for refined building techniques and systems capable of achieving the desired degree of flexibility. This was not restricted simply to product or building-compo- nent level, it also addressed the level at which products, components and activities were coordinated. Obstacles arose because, in some cases, innovative systems at building component level were still insufficiently mature (floor-, wall-, installation-, and façade systems) or because there was a lack of innovation at the level of the overall concept. "Nevertheless, these obstacles to IFD building and to innovations in construction also represent challenges for the future" (Decisio 2006).

\section{Structure and organisation of the building process}

While building technology itself is undoubtedly an essential element in achieving a flexible dwelling that is capable of meeting the needs and demands of the user, the associated organisational aspects are no less important. Consumer-oriented construction and the use of innovative construction sys-

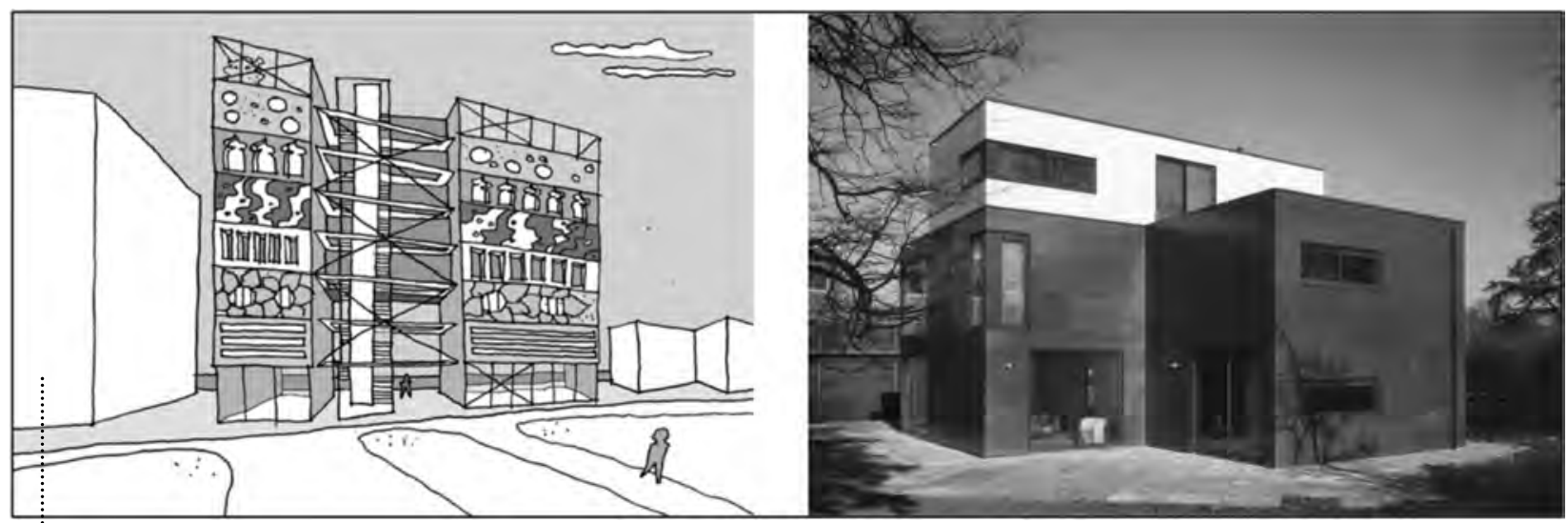

Figure 2\&3. Suspension of the IFD project 'De zeven hemels' - The seven heavens (by Crone 2007) (left)

Smarthouse; just a demonstration home (by Crone 2007) (right) 


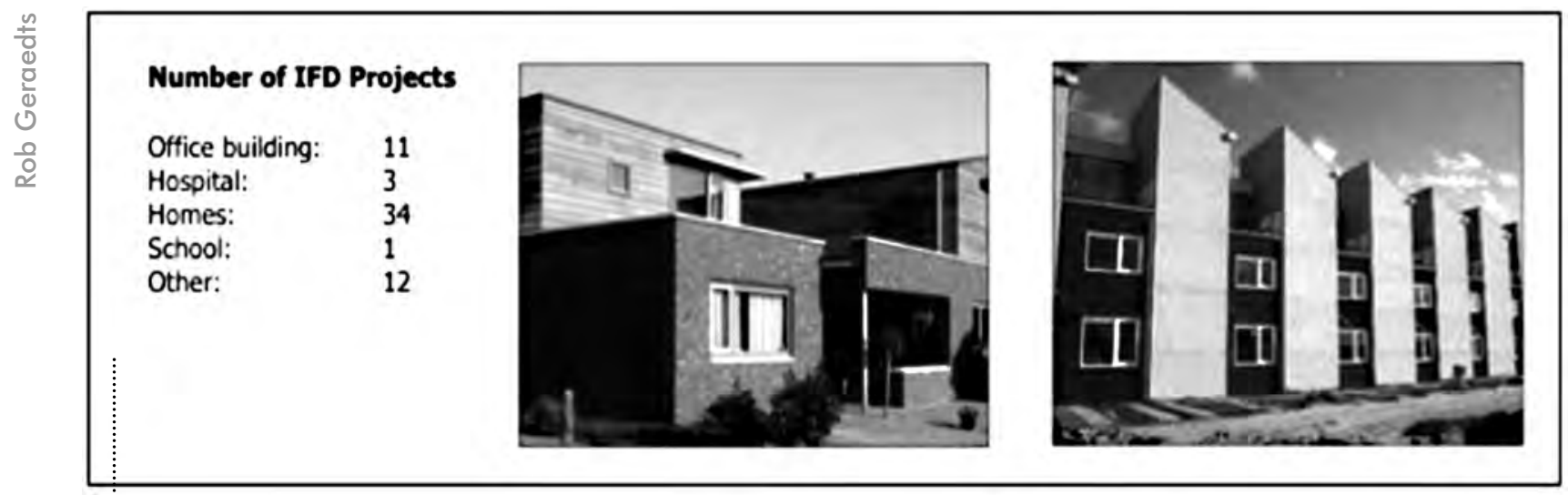

Figure 4. Number and nature of IFD projects (by Crone 2007)

tems affected the structure of the building process itself. Exploratory talks (Gunst 2008) revealed that the organisational aspects of IFD building had a major influence on the final result. Both projectbased thinking and process-based thinking are important here. How do you keep a grip on cost, quality and time in an IFD building project? This required a different approach to the process.

\section{PROBLEM DEFINITION AND RESEARCH AIM}

IFD house-building projects are still in the experimental stages. Existing obstacles to the building process mean that the aim - to build in a consumer-focused manner - is not being achieved. How can one create optimal conditions for a building process involving an IFD house-building project such that the aims - focused on consumer-oriented building and specified at the start of the IFD housebuilding project - can be achieved? The aim of the study was to provide insight into ways of optimising the building process in IFD house-building projects, by removing as many obstacles as possible and by exploiting all available opportunities. The results are intended for real estate developers, architects, builders, materials suppliers and end-users who wish to create flexible homes the IFD way.

A questionnaire was sent to real estate developers, architects and construction companies involved in twelve IFD house-building projects. The purpose was to obtain an insight into the aims specified for IFD house-building projects, and to discover which of these aims are not being achieved, and why. This survey formed the basis for the case studies. Five IFD house-building projects were studied in detail and the parties involved were interviewed (figure 5).

\section{Objectives at the start of IFD projects}

At the start of IFD house-building projects, various objectives are established in relation to Consumeroriented building, Industrial building, Flexible building, and Demountable building (see also figure 1). The main objective of these IFD house-building projects was consumer-oriented building. The IFD concept was seen as a strategy that enabled consumers to influence projects in an efficient and manageable way. Various aspects of the flexibility objectives were developed on a project-by-project basis. Most of the objectives with regard to flexibility were at the level of the dwelling's volume, layout, built-in facilities, and appearance. The individual projects each interpreted these objectives in their own way, in addition to setting objectives of their

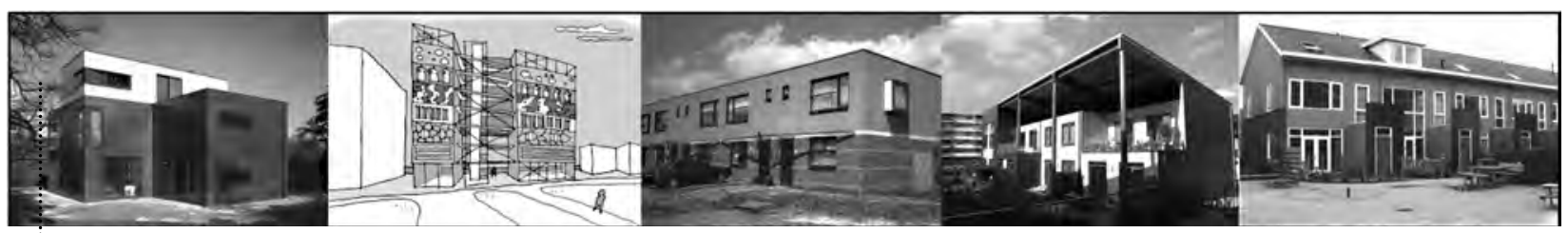

Figure 5. The five detailed cases: Smarthouse (Rotterdam), De Zeven Hemels (Rotterdam), A+ dwellings (EttenLeur), Het Masker (Veenendaal), Terbregse.nl (Rotterdam) - (by Crone 2007)

$-56$ 


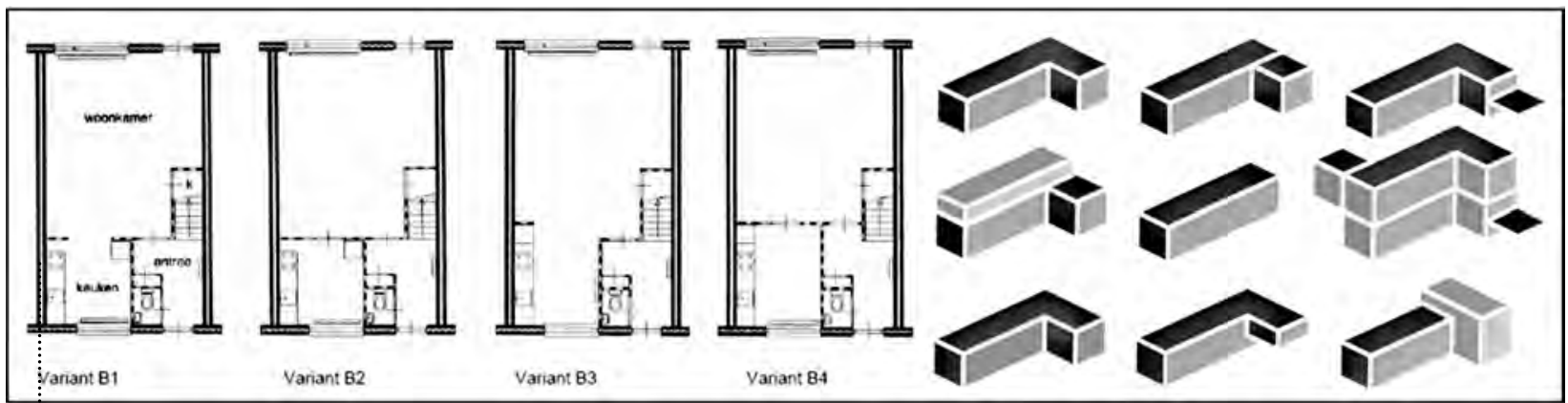

Figure 6. Flexibility in dwelling layout (left: $A+$ homes) and in the volume of the dwelling (right: Smarthouse);

(by www.slimbouwen.nl May 2010)

own. The agreement was that each project would draw a distinction between freedom of choice for the initial user (concerning the dwelling's size, layout, built-in facilities, finishing and appearance) and adaptability in the later stages of use (adjusting the size of the dwelling by adding or removing various parts, changing the floor plan, façade elements, extensions), through the use of detachable building components.

Prior agreements concerning such things as standard dimensions, details, and fixed prices per product or per $\mathrm{m} 2$ make it possible to provide guarantees concerning the end product. Efforts to accelerate the building process focus on making the maximum use of the available production technology, involving fixed agreements on dimensions, suppliers and implementation, all of which make it possible for industrially prefabricated products to be assembled and fitted on site. The use of factory-like production processes under controlled conditions makes builders independent of weather conditions, while providing a more comfortable working environment.

\section{OBJECTIVES NOT ACHIEVED - AND THE REASONS WHY}

The various parties involved indicated that, in practice, some objectives are not achieved (Gunst 2008). The principle causes put forward to account for this were: impediments in the development and construction process, projects that folded before they could be realised, lack of scope for creating a more efficient building process, product innovation that was mainly at component level rather than at the level of an overall concept, inability to provide guarantees due to a lack of coordination and cooperation between the various parties involved. The three most common reasons for failing to achieve objectives were technical, financial or organisational in nature (see figure 7). On the basis

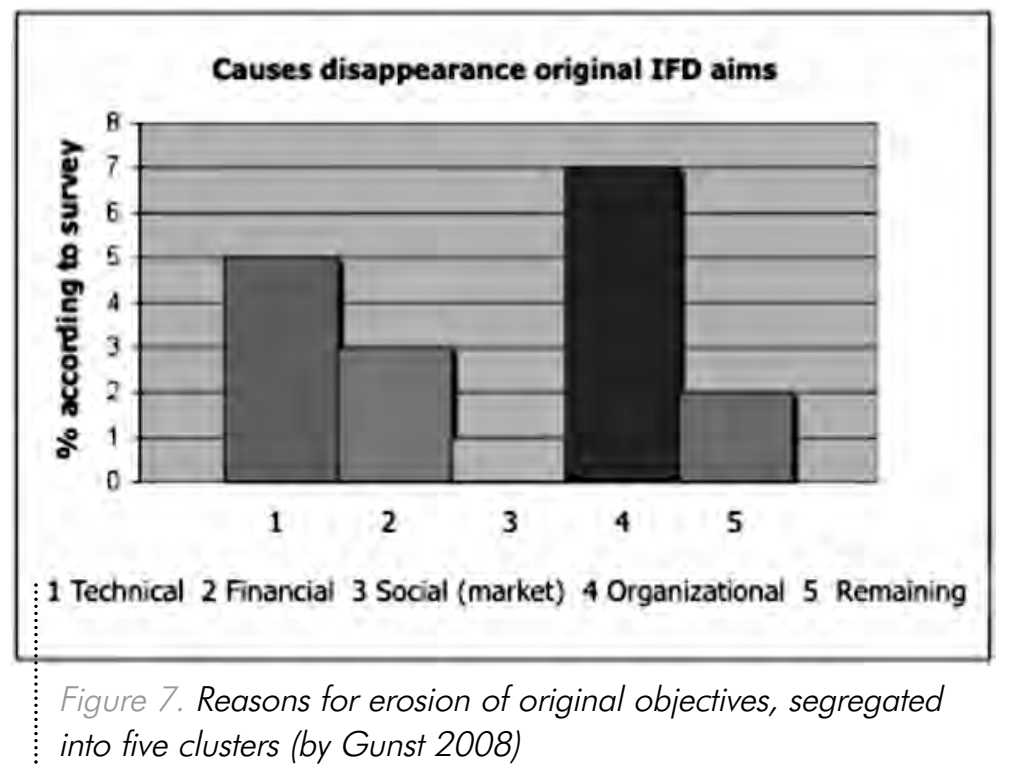




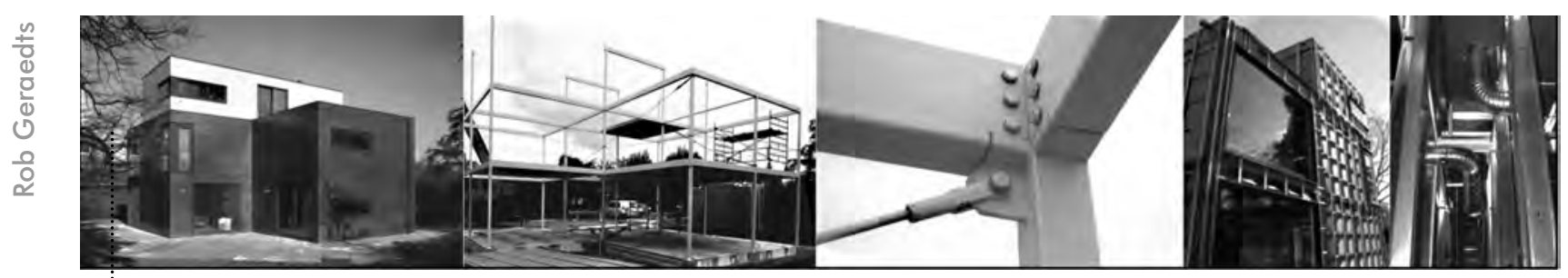

Figure 8. Smarthouse; the objective was to build detached IFD dwellings using standard building technology and organisational principles. Ultimately only a single prototype dwelling was constructed. Further developments of Smarthouse homes failed to materialise (by www.staalframebouw.nl May 2010)

of five projects, a further analysis was carried out to identify the objectives formulated at the start of the project, those that were ultimately achieved, and the reasons why the remaining objectives were not achieved.

\section{Smarthouse}

The Smarthouse concept was aimed at a very specific target group, to wit private buyers with their own plot of land and an interest in specifically tailored architecture. However, there was very little demand for dwellings of this kind. While the Smarthouse had been developed for a clearly defined target group, a deteriorating housing market caused demand to ebb away before the concept could be realised. Smarthouse combined the extensive freedom of choice that is normally associated with an individual construction contract with the advantages of a dwelling selected from a catalogue: a sleek design and a streamlined building process involving serial construction. In this way, it was possible to develop products with a fixed construction time, cost, and quality.

\section{Seven Heavens}

The Seven Heavens (Zeven Hemels) concept involved some very extreme aspects of design and construction, virtually all of which were highly inno- vative in nature. This was an entirely new concept, IFD building. This involved novel aspects such as a building system based on a steel-skeleton that had never before been used in practice, an unknown end product in the form of a flexible apartment block with eight different façades, unknown buyers (no potential clients had yet signed up), a new form of cooperation (a single basic-frame architect and seven different architects specialising in built-in facilities or in the finish of dwellings).

Market research carried out in the initial stage revealed that the project was excessively ambitious, both in view of the assigned site and of the new concept of IFD building. There was a lack of coordination between the principal on the one hand and the architects (basic-frame architect and seven architects specialising in built-in facilities or in the finish of dwellings) on the other. This meant that the project was not viable, and that it ultimately had to be abandoned.

\section{At dwellings}

The $A+$ building system concept was already in place prior to the start of the IFD programme. However, its application in housing construction was an innovative aspect. The $A+$ building system makes it possible to implement a range of different housing plans and to adapt these plans to fit
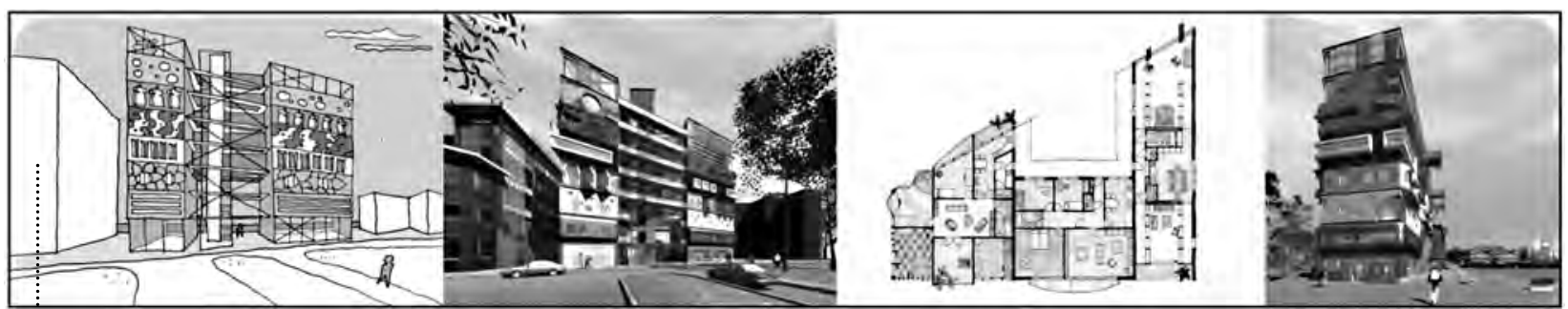

Figure 9. The goal was to respond to users' specific requirements by offering them complete freedom of choice with regard to their future dwelling's facade and layout. This project never got off the ground (by www.woonen.nl May 2010) 


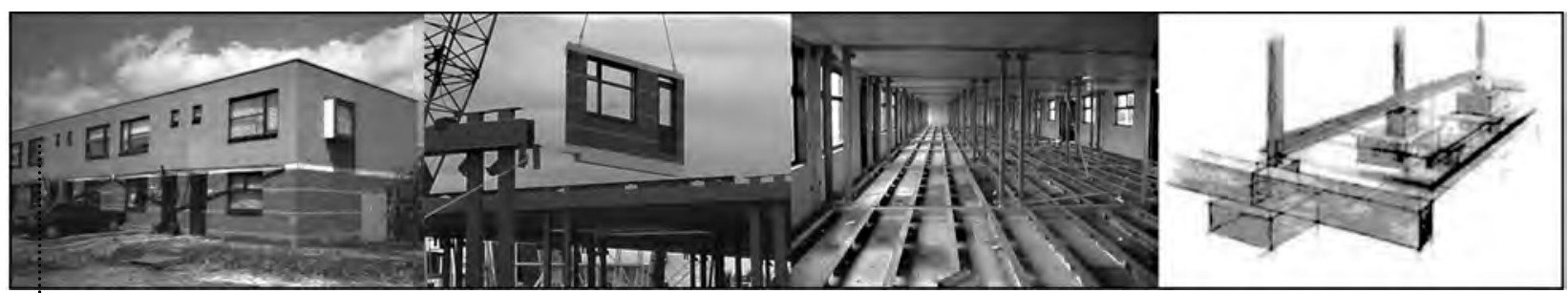

Figure 10. The objective of the IFD project $A+d$ wellings was to create homes that are adaptable to the composition of families and to changing housing needs. The Infra + floor contributed to this flexibility (by www.slimbouwen.nl May 2010)

changing housing needs. However, the users (tenants and buyers) did not become involved until after completion. Accordingly, any design modifications to meet the needs and demands of future occupants could not be fleshed out in the construction stage. Inevitably, traditional ways of thinking and working had to make way for more innovative approaches. While innovative construction systems were used, there was no coordination with those involved in the associated organisational and building work.

\section{The Mask}

Not only has The Mask (Het Masker) project been completed but it also achieved the flexibility objectives. The choice of building system substantially influenced the building process. The result was a totally different process. The preparation stage was much more intensive than had been expected, which meant that coordination between the various disciplines involved was crucial. However, the various parties failed to contribute and coordinate their expertise. The residents made full use of their freedom of choice during the construction process, at the levels of dwelling volume and layout. As the dwellings in question are rental properties that are managed by a housing association, future adjustments to changing housing needs are expected.

\section{Terbregse.nl}

The Terbregse.nl project was completed as a direct result of previous flexibility projects by the same developer. Previous in-house experience in building flexible homes in an industrial and demountable way was harnessed in this project. The nature of the approach to consumers contributes to the freedom of choice and degree of adaptability of the dwellings. The first step, involving the registration of future residents, is followed by a 'Dream House' day, after which general wishes are translated into

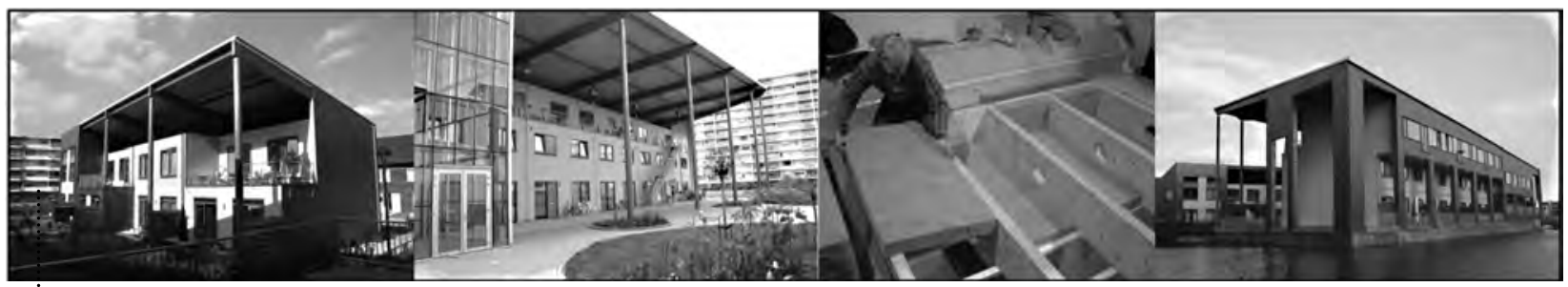

Figure 77. The scope of The Mask was the development of housing within the housing benefit limit while giving users the freedom to design their own home (by Het Houtblad April 2010)

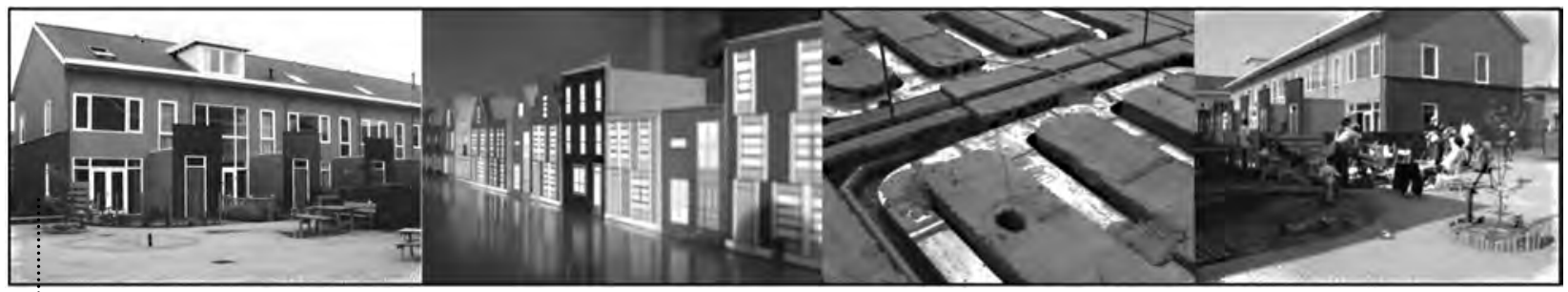

Figure 12. Niihuis (a developer and building contractor) had been building in accordance with the IFD concept for some time before the SEV came up with the IFD innovation programme. They had already come up with solutions to problems that they had encountered in previous projects (by www.terbregse.nl May 2010) 
specific design features. Next, comes the layout of the house, plot selection, the exchange of contracts, and construction. Integrated design was the most important stage in the construction process, and was already well developed. This made it possible to achieve a good rapport between the parties involved, as a result of which the implementation stage went very smoothly indeed. The only issue was that some users were too late in making their views known, which meant that the flooring system could not be adapted to individual requirements.

\section{CONCLUSIONS AND RECOMMENDATIONS}

The study has shown that some predetermined goals for the experimental IFD projects were not achieved during implementation. This is mainly due to the building and organisational aspects of the building process associated with IFD house-building projects.

The production of flexible housing that allows initial users the freedom of choice to design the dwelling to suit their own requirements and that guarantees adaptability to changing housing needs as time goes by, calls for a new approach to building processes. The use of industrially manufactured, removable building elements allows dwellings to be completed in much less time than is possible using traditional building processes. The preparatory stage, however, is much more intensive. Furthermore, the design work and the technical implementation are fully integrated, and run concurrently. When attempting to optimize the construction process, it is vital that the following aspects be addressed:

- Defining the target group for whom dwellings are being constructed is the basis of a successful project. This involves market research and an understanding of the needs and requirements of the target group in question.

- The premise and the objectives are formulated on the basis of the selected target group and the agreed definition of the "IFD building" concept. These will have to be monitored throughout the entire process.

- Consumers tend to have traditional views. They want to know what the end product will look like. Given the extreme flexibility of these dwellings, there are few standard aspects that can be used to show what the final product will look like. Accordingly, buyers often prefer a traditionally built house. The development of a demonstration home, or prototype, can help to address these concerns.

- Before all aspects of the building process have been determined, the degree of user involvement should be determined. This might relate to their ability to influence the end-result, for example, or to the process of drafting the schedule of requirements, the design process, and choice of building system.

- Many problems arise due to inexperience (and a lack of familiarity) with innovative products and processes on the part of those involved.

- The expertise of each of the various parties should be deployed at the appropriate stage. Traditional ways of thinking and working will have to make way for an integrated approach. - Integrated design offers the opportunity to achieve an optimal end product. The expertise of the various parties involved is deployed as part of a joint effort to achieve a design and to work out the relevant technical details. This requires close coordination and harmonisation between the various disciplines.

- The intended degree of flexibility will have to be translated into a design. This presents opportunities with regard to the technical aspects of building. For example, the design of a load-bearing construction that can be divided into lots, integrating flexible floor and wall systems into the design, or the creation of overcapacity.

- The shift of intensity from the implementation stage to the preparation stage means that coordination of the various market actors is crucial. It is preferable to work with fixed co-makers, in order to optimise the coordination and cooperation of the various parties. Fixed agreements can be made with them at an early stage of the building process, concerning price, quality, logistics and the supply of products.

- The full potential of product flexibility can be employed to cater for changing housing needs while the dwelling is in use. However, these 
need to be monitored and supervised to avoid the erosion of knowledge over time, concerning what is and is not possible.

\section{SEVEN STEPS IN THE GUIDELINE FOR IFD HOUSE-BUILDING PROJECTS}

The study's conclusions and recommendations form the basis of the IFD House-building Project Guidelines (Gunst 2008). These consist of seven steps that must be completed before the development of an IFD house-building project can commence.

\section{Step 1: Market research}

Launch market research in the initiation stage. On the basis of the results obtained, select the appropriate target group and the associated living requirements for which the flexible dwelling is to be built. This provides a better guarantee that the new homes will be sold.

\section{Step 2: Draft the initial guiding principles}

The principles to be drawn up involve generating a definition for the concept of IFD building, the development concept of flexible housing (e.g. private contractor, catalogue-style construction, or a concept involving a specific building system), and the approach to future users (for the user, with the user and/or by user).

\section{Step 3:Formulate objectives}

Formulate objectives in the initiation stage that can be subdivided into a central or general objective of creating value (or added value) for the user, and peripheral objectives specifically aimed at industrial, flexible, and demountable building. Monitor and check these objectives throughout the remaining stages of the process.

\section{Step 4: Select method}

In the initiation stage, select the method to be used during the development and building process. Allowance should be made for the amount of freedom of choice available to the residents during the development stage and for the degree of adaptability while the dwelling is in use. Choose an innovative building system that is best able to provide the desired flexibility. Suppliers' expertise may be useful in this regard. Determine an organisational structure and identify the parties involved and their individual responsibilities within the process and in terms of the end result.

\section{Step 5: Monitoring flexibility in the design stage}

Structure the design stage such that the principles and objectives are translated into a design. From the point of view of market research, the identification of user needs and the schedule of requirements, guarantees must be given during the design stage concerning the freedom of choice available with regard to house size, house layout, installation, built-in facilities, and finishing. Adaptability while the dwelling is in use should also be monitored, such as adding or removing various parts of the house, or making changes to its layout or appearance.

\section{Step 6: Structuring implementation stage}

Structure the implementation stage such that the flexible dwelling can be completed quickly, without encountering any obstacles. This might involve implementation logistics, on-site assembly techniques for industrially manufactured prefabricated building components, and working with fixed comakers. This involves cooperation between the contractor and specialist subcontractors and suppliers. The advantage of established teams is that the representatives of the various disciplines are used to working with one another. Each other's knowledge and expertise are utilised to the full.

\section{Step 7: Monitoring flexibility options}

Create flexibility options while the dwelling is in use and ensure that these can actually be implemented should the need arise. If a dwelling remains in the ownership of a corporation, then the latter is responsible for making the options for adaptation or change as clear as possible. When the user owns a dwelling, the latter must be provided with a logbook in which the various modification options are described and explained.

A final important recommendation relates to experimenting with innovations, both at building-component level and at the level of an overall concept. This offers an opportunity to identify potential 
obstacles at an early stage. Experimentation involves learning from experience, optimising, and perfecting. Setting up a demonstration home can be part of this procedure.

\section{REFERENCES}

BOUWMEESTER, H. 2004, SEV (red.), Demonstratieprojecten IFD bouwen, Continuiteit in IFD (Demonstration Projects IFD Construction; continuity in IFD), Drukkerii Goos, Ouderkerk aan den IJssel.

CRONE, J. 2007, Leren door demonstreren; de oogst van 7 jaar IFD bouwen (Learning by illustrating; the benefits of 7 years experimenting), Line Up Mediaservices, Boxtel.

DECISIO 2006, Beleidsevaluatie Demonstratieprogramma IFD bouwen (Management Evaluation Demonstration program (FD), Amsterdam.

GUNST, C. 2008, IFD Bouwen; flexibele input leidt tot flexibele output (IFD Construction); TU Delft, RE\&H, Delft.

Author's Address

Rob Geraedts

Delft University of Technology

Delft, The Netherlands

r.p.geraedts@tudelft.nl

- 62 